\title{
Partnerships Can Help Drive Gender Equality
}

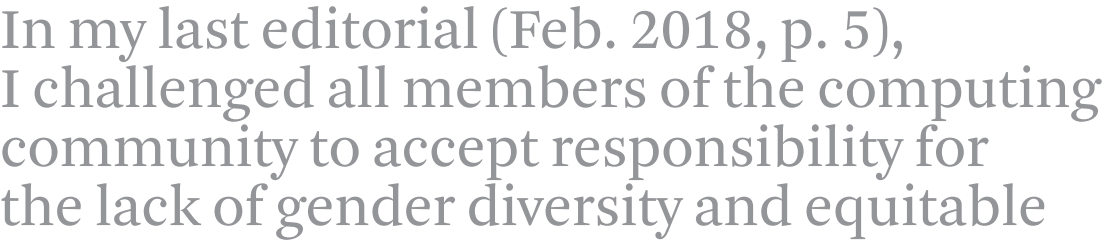

experiences of women in our field. I also encouraged broad participation in the work necessary to realize positive change, particularly by those outside of the minority group.

Here, my focus shifts to the myriad organizations whose primary mission is to work toward an increase of women in the technology sector and/or to positively impact the experience of those women already in computing.

Each of these organizations has a unique sphere in which it works. Some seek to equip women and girls with technical skills that raise their level of interest in the field and open new educational or employment opportunities. Some work in the $\mathrm{K}-12$ sector, others in higher education, and others with professional women. Some organize major events with a focus on celebrating and mentoring women while others provide local communities of support for social interaction and professional development.

All of these organizations do valuable work and I applaud those who give unselfishly of their time and talents to make that work possible. But lately I have found myself in numerous conversations that raise some important questions:

- Are we achieving all that we can or are we possibly reducing our collective impact because we are sometimes (frequently unknowingly) competing rather than cooperating for funding and volunteer effort?

- Could the large investment of time and financial resources be more impactful if organizations identify ways in which their work intersects, and build partnership programs in those spaces?

I have seen firsthand the value of partnerships in my work within ACM-W. I will highlight two of these partnerships as prime examples of collective impact.

The Computing Research Association Committee on Widening Participation (CRA-WP) annually runs a program called Grad Cohort. This three-day workshop brings together women who are currently pursuing a master's or Ph.D. in computing with goals of encouraging persistence in the field and increasing the number of women who choose to pursue research careers. Because of funding restrictions, Grad Cohort attendees must be attending universities in the U.S. and Canada. For the past three years, ACM-W has sponsored faculty from several countries to attend the Grad Cohort workshop, with a goal of creating comparable programs internationally. CRA-WP organizers have provided valuable advice on organizing similar events. As a result, Grad Cohort workshops have been held in such locations as Greece, Ireland, India, Kuwait, Spain, and soon, Turkey.

The National Center for Women in Information Technology (NCWIT) is another U.S.-based organization that provides resources and programming for $\mathrm{K}-12$, university, and professional groups. NCWIT's Aspirations in Computing (AiC) awards program honors
K-12 women, gender-queer, and nonbinary students for their computing achievements and interests and encourages them to pursue their interest in technology. This past November, the ACM Canadian Celebration of Women in Computing (CAN-CWiC) ran a pilot of the AiC program. Twentynine nominees from across Canada attended $\mathrm{CAN}-\mathrm{CWiC}$ and were recognized during the conference for their achievement. Going forward, ACM-W and NCWIT will collaborate with other non-U.S. Celebrations to launch similar programs in their regions.

These endeavors were successful because the leadership of the respective organizations came together and talked about could be leverage the mission and strengths of each individual organization could be leveraged to realize a larger impact.

It does not matter if an organization is large and globally recognized or small and working in a localized region. There is some way in which the mission and programs of each organization align with others. I challenge all who lead to be intentional in seeking out ways in which their organization can merge forces, pool resources, and work together for the greater good. Cooperation, not competition, will move the needle faster for women in computing.

Jodi Tims (jodi.tims@northeastern.edu) is Professo of the Practice and Director of CS Programs for Northeastern University-San Francisco/Silicon Valley. She has served as chair of ACM-W since July 2017. Copyright held by author. 